\title{
The Pivotal Role of TBK1 in Inflammatory Responses Mediated by Macrophages
}

\author{
Tao Yu, Young-Su Yi, Yanyan Yang, Jueun Oh, Deok Jeong, and Jae Youl Cho
}

Department of Genetic Engineering, Sungkyunkwan University, Suwon 440-746, Republic of Korea

Correspondence should be addressed to Jae Youl Cho, jaecho@skku.edu

Received 22 September 2012; Revised 3 November 2012; Accepted 7 November 2012

Academic Editor: Sunil Kumar Manna

Copyright () 2012 Tao Yu et al. This is an open access article distributed under the Creative Commons Attribution License, which permits unrestricted use, distribution, and reproduction in any medium, provided the original work is properly cited.

Inflammation is a complex biological response of tissues to harmful stimuli such as pathogens, cell damage, or irritants. Inflammation is considered to be a major cause of most chronic diseases, especially in more than 100 types of inflammatory diseases which include Alzheimer's disease, rheumatoid arthritis, asthma, atherosclerosis, Crohn's disease, colitis, dermatitis, hepatitis, and Parkinson's disease. Recently, an increasing number of studies have focused on inflammatory diseases. TBK1 is a serine/threonineprotein kinase which regulates antiviral defense, host-virus interaction, and immunity. It is ubiquitously expressed in mouse stomach, colon, thymus, and liver. Interestingly, high levels of active TBK1 have also been found to be associated with inflammatory diseases, indicating that TBK1 is closely related to inflammatory responses. Even though relatively few studies have addressed the functional roles of TBK1 relating to inflammation, this paper discusses some recent findings that support the critical role of TBK1 in inflammatory diseases and underlie the necessity of trials to develop useful remedies or therapeutics that target TBK1 for the treatment of inflammatory diseases.

\section{Introduction}

Inflammation is the immune response of tissues to pathogens, cell damage, or irritants [1]. It is a protective mechanism used by organisms to remove injurious stimuli. In the process, several symptoms appear, which include redness, swelling, and pain, which are general responses to infection. Inflammation is classified as either acute or chronic. Acute inflammation is the initial response of the organism to harmful stimuli and is induced by the increased movement of plasma and leukocytes from the blood into the injured sites. Chronic inflammation leads to a progressive shift in the type of cells present at the site of inflammation and is characterized by simultaneous destruction and generation of the tissues from the inflammatory process. Inflammation is considered to be the main cause of most chronic diseases including not only inflammatory diseases, such as heart disease, diabetes, Alzheimer's disease, and arthritis, but also cancers [2-5]. Therefore, the study of inflammation should be considered a priority.

The inflammation that occurs during innate immune responses is largely regulated by macrophages $[6,7]$. This inflammation is driven by immunopathological events such as the overproduction of various proinflammatory cytokines, including tumor necrosis factor (TNF- $\alpha$ ), interleukin (IL$1 \beta$ ), interferon (IFN- $\beta$ ), and several types of inflammatory mediators, including nitric oxide $(\mathrm{NO})$ and prostaglandin $\mathrm{E}_{2}$ $\left(\mathrm{PGE}_{2}\right)$ [8]. The production of these inflammatory mediators depends on the activation of pattern recognition receptors (PRRs), including dectin-1, Toll-like receptors (TLR-3 and TLR-4), which are induced by microbial ligands such as lipopolysaccharide (LPS) and polyinosinic:polycytidylic acid (poly $(\mathrm{I}: \mathrm{C}))[6,9,10]$. In this signaling process, several kinds of intracellular proteins are activated, which is followed by the activation of transcription factors, such as nuclear factor $(\mathrm{NF}-\kappa \mathrm{B})$, activator protein $(\mathrm{AP})-1$, and interferon regulatory factors (IRF-3 and IRF-7) [6,9].

A variety of intracellular proteins can initiate the induction of inflammatory responses. TBK1 (TANK STRAF (TNF (tumor necrosis factor) receptor-associated factor)associated NF- $\kappa \mathrm{B}$ activator\}-binding kinase 1), also called NAK (NF- $\kappa \mathrm{B}$ activating kinase) and $\mathrm{T} 2 \mathrm{~K}$, is a serine/threonine-protein kinase that is encoded by the $t b k 1$ gene. TBK1 is a member of the I $\kappa$ B kinase (IKK) family 
and shows ubiquitous expression. It has been demonstrated that TBK1 plays an important role in the regulation of the immune response to bacterial and viral challenges $[11,12]$. TBK1 has the ability to regulate the expression of inflammatory mediators such as IL- 6, TNF- $\alpha$, and IFN- $\beta$ $[11,13,14]$. Moreover, TBK1 is involved in the insulin signaling pathway, which mediates the phosphorylation of the insulin receptor at serine 994 [15] and is also involved in dietary lipid metabolism [16]. Additionally, activation of the TBK1 signaling pathway could be a novel strategy to enhance the immunogenicity of DNA vaccines [17]. Taken together, these findings suggest that TBK1 acts as a critical player in various immunobiological and immunopathological events, especially inflammatory responses.

Interestingly, TBK1 is expressed in mouse stomach, small intestine, lung, skin, brain, heart, kidney, spleen, thymus, and liver, and at especially high levels in testis $[18,19]$. In some inflammatory disease animal models, such as colitis and hepatitis animal models, levels of the active form of TBK1 are elevated compared to nondisease groups (unpublished data). A rheumatoid arthritis animal model has been especially helpful in proving a strong positive relationship between TBK1 and this disease [20]. These observations strongly suggest that TBK1 is closely related to inflammatory diseases. The purpose of this paper is to summarize recent findings and describe the central role of TBK1 in inflammatory response. We hope this paper will provide insight and attract more attention to the study of TBK1 as it relates to inflammation.

\section{Structure and Function of TBK1}

2.1. TBK1. TBK1 is a 729 amino acid protein which has four functionally distinct domains; a kinase domain (KD) at the $\mathrm{N}$-terminus, two putative coiled-coil-containing regions in the C-terminal region, including a C-terminal leucine zipper (LZ) and a helix-loop-helix (HLH) motif; a ubiquitin-like domain (ULD) $[21,22]$ (Figure 1). The ULD is a regulatory component of TBK1 and is involved in the control of kinase activation, substrate presentation, and downstream signaling pathways [21]. The LZ and HLH motifs mediate dimerization, which is necessary for their functions [23].

TBK1 is one of the IKK protein kinase family members that show ubiquitous expression. The IKK family includes two groups: the canonical IKKs such as IKK $\alpha$, IKK $\beta$, and IKK $\gamma$ (NEMO) and the noncanonical IKKs such as IKK $\varepsilon$ and TBK1 (Table 1). Among the members of this family, TBK1 exhibits $49 \%$ identity and $65 \%$ similarity with IKKE, and IKK $\alpha$ and IKK $\beta$ show similar sequence identity [19]. Despite their sequence similarity, TBK1 and IKKE exhibit differential expression patterns. TBK1, like IKK $\alpha$ and IKK $\beta$, is ubiquitously expressed, whereas IKKE expression is restricted to particular tissue compartments, with higher levels detected in lymphoid tissues, peripheral blood lymphocytes, and the pancreas $[18,20]$. In addition, LPS and TNF- $\alpha$ are also known to activate NF- $\kappa$ B via the involvement of TBK1 and $\mathrm{IKK} \varepsilon$ [24]. Due to these partially overlapping characteristics, $\mathrm{TBK} 1$ and $\mathrm{IKK} \varepsilon$ are functionally more similar to each other than to other canonical IKKs [25]. Moreover, mouse and human TBK1 proteins share over 99\% homology, indicating that this protein is highly conserved in mammals [18].

2.2. TBK1 Substrate Proteins. Studies of the substrate binding capacity of TBK1 have provided great insight into the functions of TBK1. IKK $\beta$ is a direct substrate of TBK1, and is phosphorylated at serines 177 and 181 [18]. Phosphorylation at these sites subsequently induces NF- $\kappa \mathrm{B}$ activation and inflammatory responses [18]. Sec5 and DDX3X, which are critical for interferon induction, are also substrates of TBK1 $[40,41]$. In addition, AKT (protein kinase B) is a newlyindentified substrate of TBK1. AKT is phosphorylated at serine 476 and activates the IRF3 signaling pathway, which can regulate interferon production and antiviral defense $[42,43]$. However, there may be other direct substrates that remain to be discovered, especially in NF- $\kappa \mathrm{B}$-involved signaling pathways since TBK1 strongly induces $\mathrm{NF}-\kappa \mathrm{B}$ activity [18].

2.3. TBK1 Deficiency. TBK1 deficiency could be a direct and effective way to address its functional roles. Macrophages from TBK1-knockout mice show much lower expression levels of IFN- $\beta$ and regulated and normal T cell expressed and secreted (RANTES), as well as decreased IRF3 DNAbinding activity [11]. Mice lacking TBK1 activity exhibit infiltration of immune cells in multiple tissues, including the skin, and increased susceptibility to LPS-induced lethality [11]. TBK1 deficiency also induces massive liver degeneration and apoptosis, along with a dramatic reduction in $\mathrm{NF}-\kappa \mathrm{B}$ transcription, which indicates that TBK1 is critical in protection against embryonic liver damage due to apoptosis [44]. Furthermore, TBK1 knockout fibroblastlike synoviocytes (FLS) show decreased expression levels of IFN- $\beta$ and IP-10, which are known to contribute to the occurrence of rheumatoid arthritis [20]. This observation indicates that TBK1 could play a significant role in regulating the progression of arthritis [20].

2.4. TBK1-Activated Signaling Pathways. NF- $\kappa$ B and IRF-3 activated by various TLRs are the major transcription factors involved in the induction of inflammatory mediators, such as $\mathrm{NO}, \mathrm{PGE}_{2}$, and IFN- $\beta$ [45]. TBK1 is involved in both of these signaling pathways (Figure 2) and is a critical regulator in the interferon response to viral infection $[22,35,46]$. Following activation of TLRs, TBK1 assembles with TRAF3 and TANK to phosphorylate IRF-3, -5 , and -7 at multiple serine and threonine residues [47-50]. These IRFs ultimately heterodimerize and translocate into the nucleus, where they induce expression of proinflammatory and antiviral genes such as IFN- $\alpha / \beta[51,52]$. TBK1 also acts as an NF- $\kappa \mathrm{B}$ effector. TBK 1 phosphorylates $\mathrm{I} \kappa \mathrm{B} \alpha$ at serine 32 , while IKK $\varepsilon$ phosphorylates serine 36 , which induces NF- $\kappa \mathrm{B}$ activation $[18,19,53]$. In addition, IKK $\beta, \operatorname{RelA} / p 65$, and c-Rel are also phosphorylated by TBK1 at serines 177,181 , and 536, independently, although the phosphorylation site of c-Rel has not yet been confirmed [18, 54, 55]. However, 

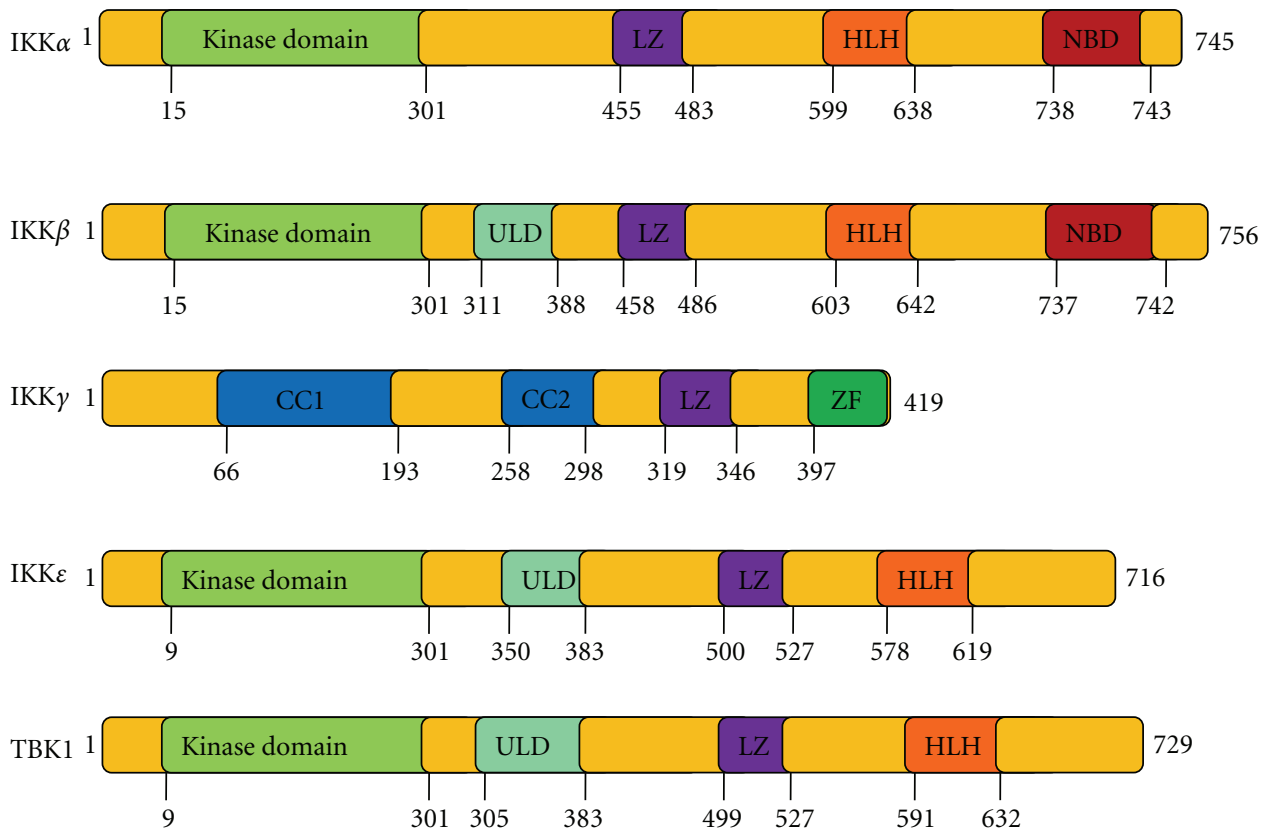

FIGURE 1: Structural and functional comparisons of the canonical and noncanonical IKKs. KD: kinase domain; HLH: helix-loop-helix; ULD: ubiquitin-like domain; LZ: leucine zipper; CC1, first coiled coil; CC2, second coiled coil; ZF: zinc finger.

TABLE 1: TBK1, IKK family, and their characteristics.

\begin{tabular}{|c|c|c|c|c|c|c|}
\hline \multirow{2}{*}{ Subtype } & \multirow{2}{*}{ Domains } & \multirow{2}{*}{ Phosphorylation site } & \multicolumn{2}{|c|}{ Sequence identity (\%) } & \multirow{2}{*}{ Function } & \multirow{2}{*}{ Reference } \\
\hline & & & $\mathrm{IKK} \alpha$ & $\mathrm{IKK} \varepsilon$ & & \\
\hline \multicolumn{7}{|c|}{$\begin{array}{l}\text { Canonical } \\
\text { IKKs }\end{array}$} \\
\hline $\mathrm{IKK} \alpha$ & $\begin{array}{l}\text { KD, LZ, } \\
\text { HLH, } \\
\text { NBD }\end{array}$ & S176/180 & 100 & 27 & $\begin{array}{l}\text { Osteoclast differentiation; skin tumor } \\
\text { suppressor; T-cell receptor signaling } \\
\text { pathway; virus response; Toll-like } \\
\text { receptor signaling pathway }\end{array}$ & [26-29] \\
\hline $\mathrm{IKK} \beta$ & $\begin{array}{l}\text { KD, ULD, } \\
\text { LZ, HLH, } \\
\text { NBD }\end{array}$ & S177/181 & 52 & 24 & $\begin{array}{l}\text { Mediates chemoresistance for cell } \\
\text { survival and death; regulates hepatic } \\
\text { fibrosis }\end{array}$ & {$[30,31]$} \\
\hline $\mathrm{IKK} \gamma$ & $\begin{array}{l}\mathrm{CC} 1, \mathrm{CC} 2 \\
\mathrm{LZ}, \mathrm{ZF}\end{array}$ & S376 & $\begin{array}{l}\text { None } \\
\text { reported }\end{array}$ & $\begin{array}{l}\text { None } \\
\text { reported }\end{array}$ & $\begin{array}{l}\text { Regulates I } \kappa \text { B kinase (IKK) complex, } \\
\text { involved in inflammation, immunity, } \\
\text { cell survival }\end{array}$ & {$[32,33]$} \\
\hline \multicolumn{7}{|c|}{$\begin{array}{l}\text { Noncanonical } \\
\text { IKKs }\end{array}$} \\
\hline $\mathrm{IKK} \varepsilon$ & $\begin{array}{l}\text { KD, ULD, } \\
\text { LZ, HLH }\end{array}$ & S172 & 27 & 100 & $\begin{array}{l}\text { Regulates type I and type II interferon } \\
\text { responses }\end{array}$ & {$[34]$} \\
\hline TBK1 & $\begin{array}{l}\text { KD, ULD, } \\
\mathrm{LZ}, \mathrm{HLH}\end{array}$ & S172 & 27 & 64 & $\begin{array}{l}\text { Regulates type I and type II interferon } \\
\text { responses, mediates NF- } \kappa \text { B signaling, } \\
\text { liver degeneration, cancer, hepatitis, } \\
\text { colitis, and rheumatoid arthritis }\end{array}$ & {$[20,22,25,28,35,36]$} \\
\hline
\end{tabular}

KD: kinase domain; HLH: helix-loop-helix; ULD: ubiquitin-like domain; LZ: leucine zipper; CC1: first coiled coil; CC2: second coiled coil; ZF: zinc finger.

$\mathrm{NF}-\kappa \mathrm{B}$ activation is for the most part normal in TBK1knockout mice, and the expression of NF- $\kappa \mathrm{B}$-target genes is only minimally decreased [22]. These results indicate that although TBK1 and IKKE are sufficient, they are not essential for NF- $\kappa \mathrm{B}$ activation, and they instead play roles in interferon signaling [22].

\section{TBK1 Functions in Macrophage-Mediated Inflammation}

Macrophages are one of the key regulators of the inflammation process. They play critical roles in the initiation, maintenance, and resolution of inflammation [56] and 


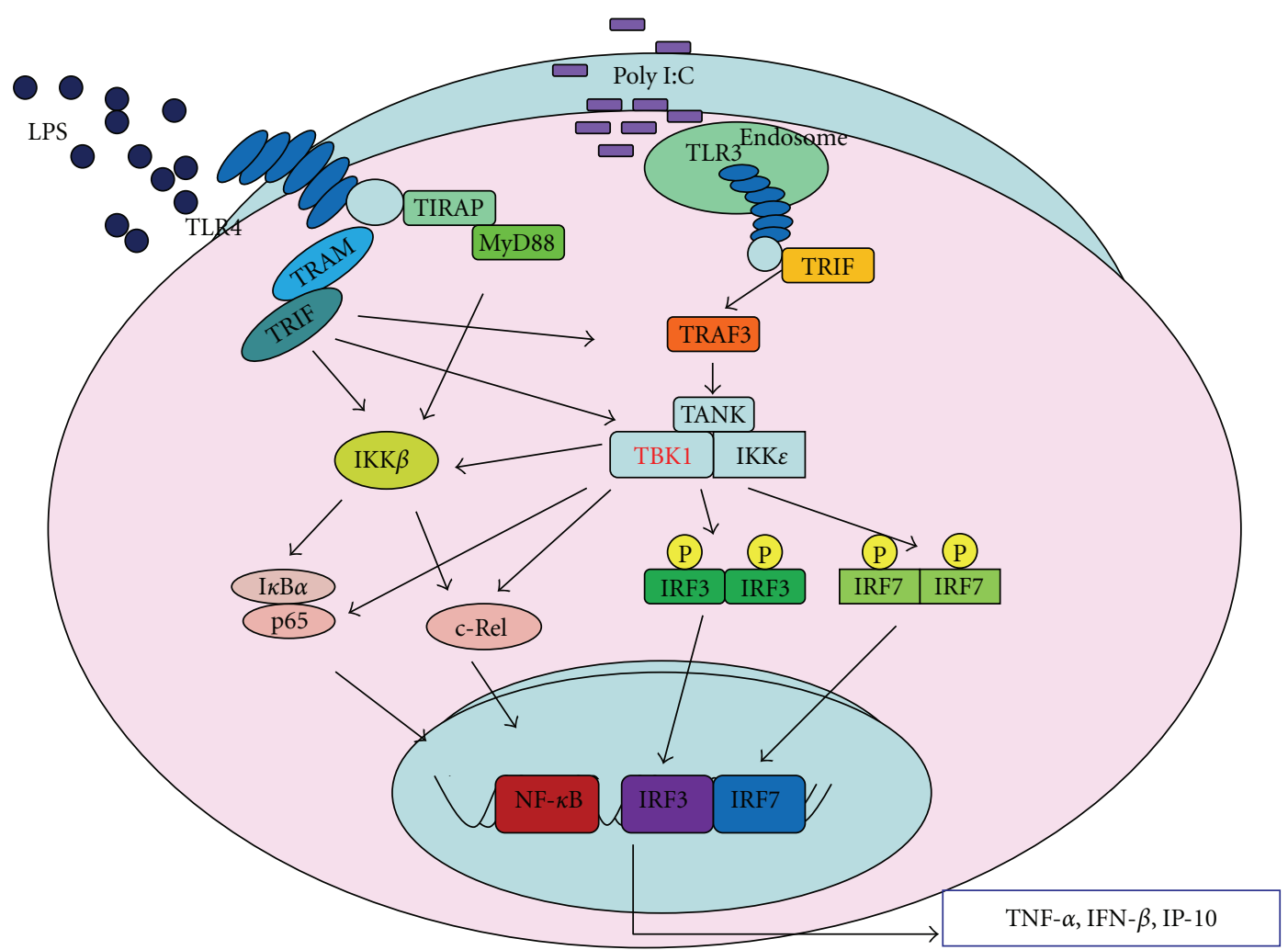

FIGURE 2: TBK1-regulated signaling pathways in inflammatory responses occurring in activated macrophages.

are activated and deactivated during the inflammatory process. Macrophages have three major functions, including antigen presentation, phagocytosis, and immunomodulation through the production of various kinds of cytokines and growth factors [56]. Once macrophages are activated by inflammatory stimuli such as bacteria-derived LPS, pam3CSK, and virus-mimicked poly(I:C), they produce various inflammatory cytokines and mediators, such as those of the IL family, TNF- $\alpha$, interferon $\alpha / \beta$, NO, and $\mathrm{PEG}_{2}$ [14, 57-60]. Therefore, macrophages, including RAW264.7 cells and peritoneal macrophages, are generally used in in vitro studies of inflammatory responses.

TBK1 is involved in the TLR3 and TLR4 signaling pathways in macrophages [61]. TBK1, especially in the TLR3 signaling pathway, acts as the central kinase directly related to the production of proinflammatory and antiviral cytokines, such as interferon $\alpha / \beta$, IP-10, and RANTES in T cells [62]. IFN- $\alpha / \beta$ signaling is critical for host defenses against various types of bacteria, including group B streptococci (GBS), pneumococci, and Escherichia coli [63]. IP-10 may play an important role in psoriatic plaques, hypersensitivity reactions, hematopoiesis, and rheumatoid arthritis [18, 64]. RANTES dramatically inhibits the cellular infiltration associated with experimental mesangioproliferative nephritis [65]. In addition, RANTES is the major HIV-suppressive factor produced by CD8 (+) T cells [66]. Furthermore, in a study by Yeh group, TBK1 deficiency was found to result in embryonic lethality; however, this event was rescued by the absence of TNFR, indicating that TBK1 is also involved in TNFR signaling [44]. Moreover, TNF- $\alpha$ expression is also dramatically induced in TBK1-overexpressing cells (unpublished data). These findings strongly indicate that TBK1 plays pivotal roles in inflammation, especially in macrophagemediated systems.

\section{Development of TBK1-Targeted Drugs as New Immunotherapeutics}

4.1. The Present Development of TBK1 Inhibitors. The significant role of TBK1 in inflammation has been recently established, and increasing numbers of compounds that target TBK1 for the treatment of inflammatory diseases have been synthesized [67]. BX795 is a well-known TBK1 inhibitor that blocks both TBK1 and $\mathrm{IKK}_{\varepsilon}$ with $\mathrm{IC}_{50}$ values of $6 \mathrm{nM}$ and $41 \mathrm{nM}$, respectively [68]. However, BX795 does not only specifically target TBK1, but also suppresses the activities of other kinases such as PDK1, TAK1, JNK, and p38, even at very low concentrations [68]. A structural understanding of BX795 and information regarding its binding sites, such as its ATP binding motif or other allosteric sites, could allow for the development of new and potent inhibitors specific to TBK1 [6]. For example, MRT67307, which is a new TBK1 inhibitor, derivatized from BX795, suppressed TBK1 activity with much higher specificity $\left(\mathrm{IC}_{50}=19 \mathrm{nM}\right)$, so that it did not inhibit other kinases such as JNK or p38 [69]. Currently, a number of potential TBK1 inhibitors with high specificity and efficacy are under development by various companies. 
TABLE 2: Naturally occurring compounds targeting TBK1.

\begin{tabular}{|c|c|c|c|}
\hline Compound & Cells & Action target of TBK1 & Reference \\
\hline Resveratrol & $\begin{array}{l}\text { Epithelial cells } \\
\text { RAW264.7 cells }\end{array}$ & Production of IL- 6 , TNF- $\alpha$, IFN-1, and iNOS & {$[13,37]$} \\
\hline Luteolin & $\begin{array}{l}\text { RAW264.7 } \\
\text { macrophage }\end{array}$ & $\begin{array}{l}\text { Expression of TNF- } \alpha \text {, IL-6, IL-12, IP-10, IFN- } \beta \text {, } \\
\text { CXCL9, and IL- } 27\end{array}$ & {$[38]$} \\
\hline Quercetin & $\begin{array}{l}\text { RAW264.7 } \\
\text { macrophage }\end{array}$ & Expression of IP-10, IFN- $\beta$ & {$[38]$} \\
\hline EGCG & $\begin{array}{l}\text { RAW264.7 } \\
\text { macrophage }\end{array}$ & TRIF-dependent signaling pathways & {$[38,39]$} \\
\hline Chrysin & $\begin{array}{l}\text { RAW } 264.7 \\
\text { macrophage }\end{array}$ & Expression of IP-10, IFN- $\beta$ & {$[38]$} \\
\hline Eriodictyol & $\begin{array}{l}\text { RAW264.7 } \\
\text { macrophage }\end{array}$ & Expression of IP-10, IFN- $\beta$ & {$[38]$} \\
\hline
\end{tabular}

4.2. TBK1 Inhibitor as a Suppressor of Production of Inflammatory Mediators. Although few specific inhibitors have been developed, large quantities of anti-inflammatory compounds that target TBK1 have been reported (Table 2). For example, resveratrol diminishes the mRNA levels of IFN-1, TNF- $\alpha$, and inducible nitric oxide synthase (iNOS) by inhibiting NF- $\kappa$ B, AP-1, and TBK1/IRF3 signaling pathways [37]. Resveratrol also decreases respiratory syncytial virus- (RSV-) induced IL-6 production in epithelial cells by suppressing TBK1 activity [13]. (-)-Epigallocatechin-3-gallate (EGCG), a flavonoid found in green tea, inhibits COX-2 expression by suppressing MyD88- and TRIF-dependent signaling pathways through direct inhibition of TBK1 activity [39]. Moreover, luteolin and its structural analogues, such as quercetin, chrysin, and eriodictyol, inhibit TBK1 kinase activity and consequently downregulate the expression of TBK1-targeted genes, including TNF- $\alpha$, IL-6, IL-12, IP-10, IFN- $\beta$, CXCL9, and IL-27 [38].

4.3. In Vivo Therapeutic Effects of TBK1-Targeted Drugs in Inflammatory Disease Models. Acute and chronic mouse models are generally used in laboratory research for in vivo tests. For example, $\mathrm{HCl} / \mathrm{EtOH}$ can induce gastritis, and dextran sodium sulfate (DSS) and acetic acid can be used to induce colitis $[14,59]$. Collagen type has the ability to induce arthritis, and bacteria-derived LPS can induce hepatitis and septic shock. These animal models can be used as representative inflammatory disease models for the testing of drug candidate efficacies $[6,14,36]$.

Currently, only a few studies have been performed to investigate TBK1-targeted treatment of inflammatory diseases. A potential inhibitor of TBK1-mediated signaling pathway is rebamipide [36], which is an amino acid derivative of $2(1 \mathrm{H})$-quinolinone. Rebamipide is widely used to treat gastric ulcers and gastric injury. In a DSS-induced colitis model, rebamipide treatment showed strong therapeutic effects through the targeting of TBK1-IRF3/7-IFN- $\alpha / \beta$ signaling pathways [36]. In addition to this result, our group has also discovered that high levels of active TBK1 are expressed in the DSS-induced colitis model, the $\mathrm{HCl} / \mathrm{EtOH}$-induced gastritis model, the LPS-induced hepatitis model, and the collagen type-II-induced arthritis model (unpublished data).
Although these results indicate that the TBK1 pathway could be a suitable target for new treatments for inflammatory diseases, only a small number of TBK1 inhibitors have been developed that far. Therefore, increased effort in the development of TBK1-targeted inhibitors is necessary.

\section{Summary and Perspective}

A great number of studies have reported that TBK1 plays pivotal roles in cancers, diabetes, and bacterial and virus infections, especially in inflammatory diseases, including colitis, rheumatoid arthritis, hepatitis, and atherosclerosis. These cumulative studies may provide the essential clues and insights needed for the development of therapeutic strategies against the various diseases involving TBK1. We expect that novel and safe TBK1-targeted drugs or foods with strong efficacy will be developed in the future.

\section{Abbreviations}

TBK1: $\quad$ TANK binding kinase 1

TANK: TRAF (TNF (tumour necrosis factor)

receptor-associated factor)

NAK: $\quad$ NF- $\kappa$ B activating kinase

IKK: $\quad$ I $\kappa$ B kinase

$\mathrm{PGE}_{2}$ : $\quad$ Prostaglandin $\mathrm{E}_{2}$

TNF: $\quad$ Tumor necrosis factor

IL: $\quad$ Interleukin

iNOS: Inducible nitric oxide synthase

COX: Cyclooxygenase

TLR: Toll-like receptor

LPS: Lipopolysaccharide

Poly(I : C): Polyinosinic : polycytidylic acid

NF- $\kappa$ B: $\quad$ Nuclear factor $-\kappa$ B

AP-1: $\quad$ Activator protein-1

IKK: $\quad \mathrm{I} \kappa \mathrm{B} \alpha$ kinase

IRF: Interferon regulatory factor

JNK: $\quad$ c-Jun N-terminal kinase

LZ: C-terminal leucine zipper

HLH: Helix-loop-helix

ULD: Ubiquitin-like domain. 


\section{Authors' Contribution}

T. Yu and Y.-S. Yi equally contributed to this work.

\section{Acknowledgment}

This research was supported by the Basic Science Research Program through the National Research Foundation of Korea (NRF) funded by the Ministry of Education, Science and Technology (no. 0004975).

\section{References}

[1] L. Ferrero-Miliani, O. H. Nielsen, P. S. Andersen, and S. E. Girardin, "Chronic inflammation: importance of NOD2 and NALP3 in interleukin- $1 \beta$ generation," Clinical and Experimental Immunology, vol. 147, no. 2, pp. 227-235, 2007.

[2] N. Eiro and F. J. Vizoso, "Inflammation and cancer," World Journal of Gastrointestinal Surgery, vol. 4, no. 3, pp. 62-72, 2012.

[3] F. M. Moret, V. Badot, B. R. Lauwerys, and J. A. van Roon, "Intraarticular soluble interleukin-17 receptor levels are increased in patients with rheumatoid arthritis and correlate with local mediators of inflammation: comment on the article by Pickens et al," Arthritis and Rheumatism, vol. 64, no. 2, pp. 594-595, 2012.

[4] W. L. Yong, P. H. Kim, W. H. Lee, and A. A. Hirani, "Interleukin-4, oxidative stress, vascular inflammation and atherosclerosis," Biomolecules and Therapeutics, vol. 18, no. 2, pp. 135-144, 2010.

[5] T. Wyss-Coray and J. Rogers, "Inflammation in Alzheimer disease-a brief review of the basic science and clinical literature," Cold Spring Harbor Perspectives in Medicine, vol. 2, no. 1, Article ID a006346, 2012.

[6] Y. G. Lee, J. Lee, S. E. Byeon et al., "Functional role of Akt in macrophage-mediated innate immunity," Frontiers in Bioscience, vol. 16, no. 2, pp. 517-530, 2011.

[7] J. G. Barin, N. R. Rose, and D. Čiháková, "Macrophage diversity in cardiac inflammation: a review," Immunobiology, vol. 217, no. 5, pp. 468-475, 2012.

[8] N. Qureshi, S. N. Vogel, C. Van Way III, C. J. Papasian, A. A. Qureshi, and D. C. Morison, "The proteasome: a central regulator of inflammation and macrophage function," Immunologic Research, vol. 31, no. 3, pp. 243-260, 2005.

[9] J. P. Butchar, K. V. L. Parsa, C. B. Marsh, and S. Tridandapani, "Negative regulators of Toll-like receptor 4-mediated macrophage inflammatory response," Current Pharmaceutical Design, vol. 12, no. 32, pp. 4143-4153, 2006.

[10] S. Batbayar, D. H. Lee, and H. W. Kim, "Immunomodulation of fungal $\beta$-glucan in host defense signaling by dectin-1," Biomolecules \& Therapeutics, vol. 20, no. 5, pp. 433-445, 2012.

[11] E. Marchlik, P. Thakker, T. Carlson et al., "Mice lacking Tbk1 activity exhibit immune cell infiltrates in multiple tissues and increased susceptibility to LPS-induced lethality," Journal of Leukocyte Biology, vol. 88, no. 6, pp. 1171-1180, 2010.

[12] A. K. Perry, E. K. Chow, J. B. Goodnough, W. C. Yeh, and G. Cheng, "Differential requirement for TANK-binding kinase1 in type I interferon responses to toll-like receptor activation and viral infection," The Journal of Experimental Medicine, vol. 199, no. 12, pp. 1651-1658, 2004.

[13] X. H. Xie, N. Zang, S. M. Li et al., "Resveratrol Inhibits respiratory syncytial virus-induced IL-6 production, decreases viral replication, and downregulates TRIF expression in airway epithelial cells," Inflammation, vol. 35, no. 4, pp. 1392-1401, 2012.

[14] T. Yu, J. Shim, Y. Yang et al., “3-(4-(tert-Octyl)phenoxy) propane-1, 2-diol suppresses inflammatory responses via inhibition of multiple kinases," Biochemical Pharmacology, vol. 83, no. 11, pp. 1540-1551, 2012.

[15] M. C. Muñoz, J. F. Giani, M. A. Mayer, J. E. Toblli, D. Turyn, and F. P. Dominici, "TANK-binding kinase 1 mediates phosphorylation of insulin receptor at serine residue 994: a potential link between inflammation and insulin resistance," Journal of Endocrinology, vol. 201, no. 2, pp. 185-197, 2009.

[16] E. Schmitt, M. A. Ballou, M. N. Correa, E. J. DePeters, J. K. Drackley, and J. J. Loor, "Dietary lipid during the transition period to manipulate subcutaneous adipose tissue peroxisome proliferator-activated receptor-gamma co-regulator and target gene expression," Journal of Dairy Science, vol. 94, no. 12, pp. 5913-5925, 2011.

[17] K. Y. Chua, L. C. Kuo, and C. H. Huang, "DNA vaccines for the prevention and treatment of allergy," Current Opinion in Allergy and Clinical Immunology, vol. 9, no. 1, pp. 50-54, 2009.

[18] Y. Tojima, A. Fujimoto, M. Delhase et al., "NAK is an $\mathrm{I} \kappa \mathrm{B}$ kinase-activating kinase," Nature, vol. 404, no. 6779, pp. 778782, 2000.

[19] J. L. Pomerantz and D. Baltimore, "NF- $\kappa$ B activation by a signaling complex containing TRAF2, TANK and TBK1, a novel IKK-related kinase," The EMBO Journal, vol. 18, no. 23, pp. 6694-6704, 1999.

[20] D. ] Hammaker, D. L. Boyle, and G. S. Firestein, "Synoviocyte innate immune responses: TANK-binding kinase-1 as a potential therapeutic target in rheumatoid arthritis," Rheumatology, vol. 51, no. 4, pp. 610-618, 2012.

[21] M. J. May, S. E. Larsen, J. H. Shim, L. A. Madge, and S. Ghosh, "A novel ubiquitin-like domain in $\mathrm{I} \kappa \mathrm{B}$ kinase $\beta$ is required for functional activity of the kinase," The Journal of Biological Chemistry, vol. 279, no. 44, pp. 45528-45539, 2004.

[22] R. R. Shen and W. C. Hahn, "Emerging roles for the noncanonical IKKs in cancer," Oncogene, vol. 30, no. 6, pp. 631$641,2011$.

[23] G. Xu, Y. C. Lo, Q. Li et al., "Crystal structure of inhibitor of kappaB kinase beta," Nature, vol. 472, no. 7343, pp. 325-330, 2011.

[24] S. Sankar, H. Chan, W. J. Romanow, J. Li, and R. J. Bates, "IKKi signals through IRF3 and NF $\kappa$ B to mediate the production of inflammatory cytokines," Cellular Signalling, vol. 18, no. 7, pp. 982-993, 2006.

[25] J. F. Clément, S. Meloche, and M. J. Servant, "The IKK-related kinases: from innate immunity to oncogenesis," Cell Research, vol. 18, no. 9, pp. 889-899, 2008.

[26] A. I. Idris, M. Krishnan, P. Simic et al., "Small molecule inhibitors of $\mathrm{I} \kappa \mathrm{B}$ kinase signaling inhibit osteoclast formation in vitro and prevent ovariectomy-induced bone loss in vivo," The FASEB Journal, vol. 24, no. 11, pp. 4545-4555, 2010.

[27] S. J. Lee, M. Long, A. J. Adler, R. S. Mittler, and A. T. Vella, "The IKK-neutralizing compound bay 11 kills super effector CD8 T cells by altering caspase-dependent activation-induced cell death," Journal of Leukocyte Biology, vol. 85, no. 1, pp. 175$185,2009$.

[28] W. C. Huang, W. S. Chen, Y. J. Chen et al., "Hepatitis B virus $\mathrm{X}$ protein induces IKKalpha nuclear translocation via Akt-dependent phosphorylation to promote the motility of hepatocarcinoma cells," Journal of Cellular Physiology, vol. 227, no. 4, pp. 1446-1454, 2012. 
[29] E. Park, B. Liu, X. Xia, F. Zhu, W. B. Jami, and Y. Hu, "Role of IKK $\alpha$ in skin squamous cell carcinomas," Future Oncology, vol. 7, no. 1, pp. 123-134, 2011.

[30] T. Tezil, C. Bodur, O. Kutuk, and H. Basaga, "IKK-beta mediates chemoresistance by sequestering FOXO3, a critical factor for cell survival and death," Cellular Signalling, vol. 24, no. 6, pp. 1361-1368, 2012.

[31] J. Wei, M. Shi, W. Q. Wu et al., "IkappaB kinase-beta inhibitor attenuates hepatic fibrosis in mice," World Journal of Gastroenterology, vol. 17, no. 47, pp. 5203-5213, 2011.

[32] M. Rushe, L. Silvian, S. Bixler et al., "Structure of a NEMO/IKK-associating domain reveals architecture of the interaction site," Structure, vol. 16, no. 5, pp. 798-808, 2008.

[33] A. S. Shifera, "Proteins that bind to IKK $\gamma$ (NEMO) and downregulate the activation of NF- $\kappa \mathrm{B}$," Biochemical and Biophysical Research Communications, vol. 396, no. 3, pp. 585-589, 2010.

[34] S. L. Ng, B. A. Friedman, S. Schmid et al., "IkappaB kinase epsilon (IKK(epsilon)) regulates the balance between type I and type II interferon responses," Proceedings of the National Academy of Sciences of the United States of America, vol. 108, no. 52, pp. 21170-21175, 2011.

[35] K. A. Fitzgerald, S. M. McWhirter, K. L. Faia et al., "IKKE and TBKI are essential components of the IRF3 signalling pathway," Nature Immunology, vol. 4, no. 5, pp. 491-496, 2003.

[36] N. Ogasawara, M. Sasaki, Y. Itoh et al., "Rebamipide suppresses TLR-TBK1 signaling pathway resulting in regulating IRF3/7 and IFN- $\alpha / \beta$ reduction," Journal of Clinical Biochemistry and Nutrition, vol. 48, no. 2, pp. 154-160, 2011.

[37] M. H. Kim, D. S. Yoo, S. Y. Lee et al., "The TRIF/TBK1/IRF-3 activation pathway is the primary inhibitory target of resveratrol, contributing to its broad-spectrum anti-inflammatory effects," Pharmazie, vol. 66, no. 4, pp. 293-300, 2011.

[38] J. K. Lee, S. Y. Kim, Y. S. Kim, W. H. Lee, D. H. Hwang, and J. Y. Lee, "Suppression of the TRIF-dependent signaling pathway of Toll-like receptors by luteolin," Biochemical Pharmacology, vol. 77, no. 8, pp. 1391-1400, 2009.

[39] H. S. Youn, J. Y. Lee, S. I. Saitoh et al., "Suppression of MyD88and TRIF-dependent signaling pathways of toll-like receptor by (-)-epigallocatechin-3-gallate, a polyphenol component of green tea," Biochemical Pharmacology, vol. 72, no. 7, pp. 850859, 2006.

[40] Y. Chien, S. Kim, R. Bumeister et al., "RalB GTPase-mediated activation of the $\mathrm{I} \kappa \mathrm{B}$ family kinase TBK1 couples innate immune signaling to tumor cell survival," Cell, vol. 127, no. 1, pp. 157-170, 2006.

[41] D. Soulat, T. Bürckstümmer, S. Westermayer et al., "The DEAD-box helicase DDX3X is a critical component of the TANK-binding kinase 1-dependent innate immune response," The EMBO Journal, vol. 27, no. 15, pp. 2135-2146, 2008.

[42] S. M. Joung, Z. Y. Park, S. Rani, O. Takeuchi, S. Akira, and J. Y. Lee, "Akt contributes to activation of the TRIFdependent signaling pathways of TLRS by interacting with TANK-binding kinase 1," Journal of Immunology, vol. 186, no. 1, pp. 499-507, 2011.

[43] X. Xie, D. Zhang, B. Zhao et al., "I $\kappa$ B kinase $\varepsilon$ and TANKbinding kinase 1 activate AKT by direct phosphorylation," Proceedings of the National Academy of Sciences of the United States of America, vol. 108, no. 16, pp. 6474-6479, 2011.

[44] M. Bonnard, C. Mirtsos, S. Suzuki et al., "Deficiency of T2K leads to apoptotic liver degeneration and impaired NF- $\kappa \mathrm{B}$ dependent gene transcription," The EMBO Journal, vol. 19, no. 18, pp. 4976-4985, 2000.
[45] M. Hallman, M. RÄmet, and R. A. Ezekowitz, "Toll-like receptors as sensors of pathogens," Pediatric Research, vol. 50, no. 3, pp. 315-321, 2001.

[46] S. Sharma, B. R. TenOever, N. Grandvaux, G. P. Zhou, R. Lin, and J. Hiscott, "Triggering the interferon antiviral response through an IKK-related pathway," Science, vol. 300, no. 5622, pp. 1148-1151, 2003.

[47] S. M. McWhirter, K. A. Fitzgerald, J. Rosains, D. C. Rowe, D. T. Golenbock, and T. Maniatis, "IFN-regulatory factor 3-dependent gene expression is defective in Tbk1-deficient mouse embryonic fibroblasts," Proceedings of the National Academy of Sciences of the United States of America, vol. 101, no. 1, pp. 233-238, 2004.

[48] M. Mori, M. Yoneyama, T. Ito, K. Takahashi, F. Inagaki, and T. Fujita, "Identification of ser-386 of interferon regulatory factor 3 as critical target for inducible phosphorylation that determines activation," The Journal of Biological Chemistry, vol. 279, no. 11, pp. 9698-9702, 2004.

[49] A. Caillaud, A. G. Hovanessian, D. E. Levy, and I. J. Marié, "Regulatory serine residues mediate phosphorylationdependent and phosphorylation-independent activation of interferon regulatory factor 7," The Journal of Biological Chemistry, vol. 280, no. 18, pp. 17671-17677, 2005.

[50] T. F. Cheng, S. Brzostek, O. Ando, S. Van Scoy, K. P. Kumar, and N. C. Reich, "Differential activation of IFN regulatory factor (IRF)-3 and IRF-5 transcription factors during viral infection," Journal of Immunology, vol. 176, no. 12, pp. 74627470, 2006.

[51] R. Lin, C. Heylbroeck, P. M. Pitha, and J. Hiscott, "Virusdependent phosphorylation of the IRF-3 transcription factor regulates nuclear translocation, transactivation potential, and proteasome- mediated degradation," Molecular and Cellular Biology, vol. 18, no. 5, pp. 2986-2996, 1998.

[52] M. Sato, H. Suemori, N. Hata et al., "Distinct and essential roles of transcription factors IRF-3 and IRF-7 in response to viruses for IFN- $\alpha / \beta$ gene induction," Immunity, vol. 13 , no. 4 , pp. 539-548, 2000.

[53] T. Shimada, T. Kawai, K. Takeda et al., "IKK-i, a novel lipopolysaccharide-inducible kinase that is related to $\mathrm{I} \kappa \mathrm{B}$ kinases," International Immunology, vol. 11, no. 8, pp. 13571362, 1999.

[54] H. R. Kim, S. H. Lee, and G. Jung, "The hepatitis B viral X protein activates NF- $\kappa \mathrm{B}$ signaling pathway through the upregulation of TBK1," FEBS Letters, vol. 584, no. 3, pp. 525-530, 2010.

[55] J. Harris, S. Olière, S. Sharma et al., "Nuclear accumulation of cRel following C-terminal phosphorylation by TBK1/IKKe," Journal of Immunology, vol. 177, no. 4, pp. 2527-2535, 2006.

[56] N. Fujiwara and K. Kobayashi, "Macrophages in inflammation,” Current Drug Targets, vol. 4, no. 3, pp. 281-286, 2005.

[57] T. Yu, J. Lee, Y. G. Lee et al., "In vitro and in vivo antiinflammatory effects of ethanol extract from Acer tegmentosum," Journal of Ethnopharmacology, vol. 128, no. 1, pp. 139147, 2010.

[58] T. Yu, Y. J. Lee, H. M. Yang et al., "Inhibitory effect of Sanguisorba officinalis ethanol extract on NO and PGE2 production is mediated by suppression of NF- $\kappa \mathrm{B}$ and AP-1 activation signaling cascade," Journal of Ethnopharmacology, vol. 134, no. 1, pp. 11-17, 2011.

[59] T. Yu, H. M. Ahn, T. Shen et al., "Anti-inflammatory activity of ethanol extract derived from Phaseolus angularis beans," Journal of Ethnopharmacology, vol. 137, no. 3, pp. 1197-1206, 2011. 
[60] T. Yu, S. Lee, W. S. Yang et al., "The ability of an ethanol extract of Cinnamomum cassia to inhibit Src and spleen tyrosine kinase activity contributes to its anti-inflammatory action," Journal of Ethnopharmacology, vol. 139, no. 2, pp. 566-573, 2012.

[61] H. Hemmi, O. Takeuchi, S. Sato et al., "The roles of two $\mathrm{I} \kappa \mathrm{B}$ kinase-related kinases in lipopolysaccharide and double stranded RNA signaling and viral infection," The Journal of Experimental Medicine, vol. 199, no. 12, pp. 1641-1650, 2004.

[62] J. Huang, T. Liu, L. G. Xu, D. Chen, Z. Zhai, and H. B. $\mathrm{Shu}$, "SIKE is an IKKe/TBK1-associated suppressor of TLR3and virus-triggered IRF-3 activation pathways," The EMBO Journal, vol. 24, no. 23, pp. 4018-4028, 2005.

[63] G. Mancuso, A. Midiri, C. Biondo et al., "Type I IFN signaling is crucial for host resistance against different species of pathogenic bacteria," Journal of Immunology, vol. 178, no. 5, pp. 3126-3133, 2007.

[64] K. E. Cole, C. A. Strick, T. J. Paradis et al., "Interferoninducible $\mathrm{T}$ cell alpha chemoattractant (I-TAC): a novel nonELR CXC chemokine with potent activity on activated T cells through selective high affinity binding to CXCR3," The Journal of Experimental Medicine, vol. 187, no. 12, pp. 2009-2021, 1998.

[65] C. J. Wiedermann, E. Kowald, N. Reinisch et al., "Monocyte haptotaxis induced by the RANTES chemokine," Current Biology, vol. 3, no. 11, pp. 735-739, 1993.

[66] F. Cocchi, A. L. DeVico, A. Garzino-Demo, S. K. Arya, R. C. Gallo, and P. Lusso, "Identification of RANTES, MIP- $1 \alpha$, and MIP-1 $\beta$ as the major HIV-suppressive factors produced by CD8+ T cells," Science, vol. 270, no. 5243, pp. 1811-1815, 1995.

[67] E. G. McIver, J. Bryans, K. Birchall et al., "Synthesis and structure-activity relationships of a novel series of pyrimidines as potent inhibitors of TBK1/IKKepsilon kinases," Bioorganic \& Medicinal Chemistry Letters, vol. 22, pp. 7169-7173, 2012.

[68] K. Clark, L. Plater, M. Peggie, and P. Cohen, "Use of the pharmacological inhibitor BX795 to study the regulation and physiological roles of TBK1 and $\mathrm{I} \kappa \mathrm{B}$ Kinase $\in$ : a distinct upstream kinase mediates ser-172 phosphorylation and activation," The Journal of Biological Chemistry, vol. 284, no. 21, pp. 14136-14146, 2009.

[69] K. Clark, M. Peggie, L. Plater et al., "Novel cross-talk within the IKK family controls innate immunity," Biochemical Journal, vol. 434, no. 1, pp. 93-104, 2011. 


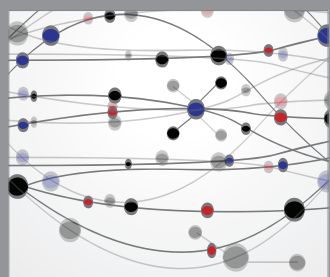

The Scientific World Journal
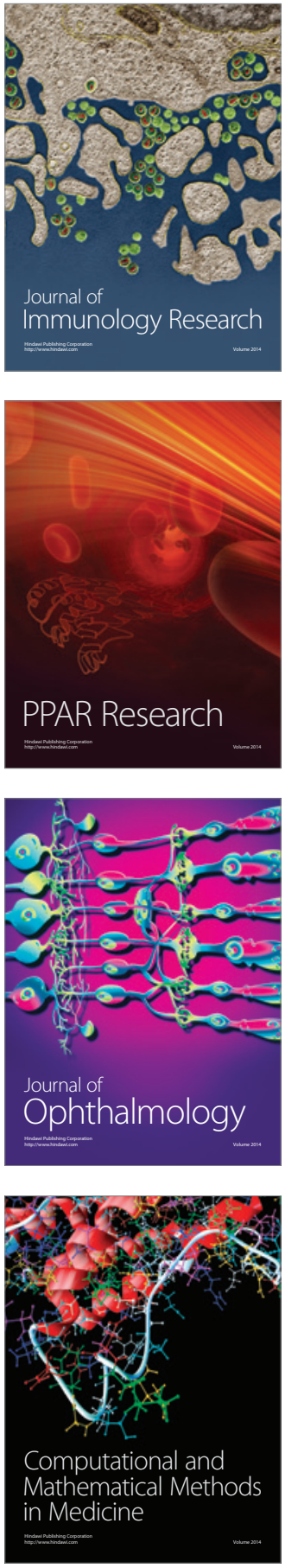

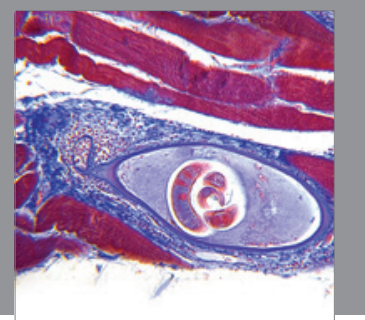

Gastroenterology

Research and Practice
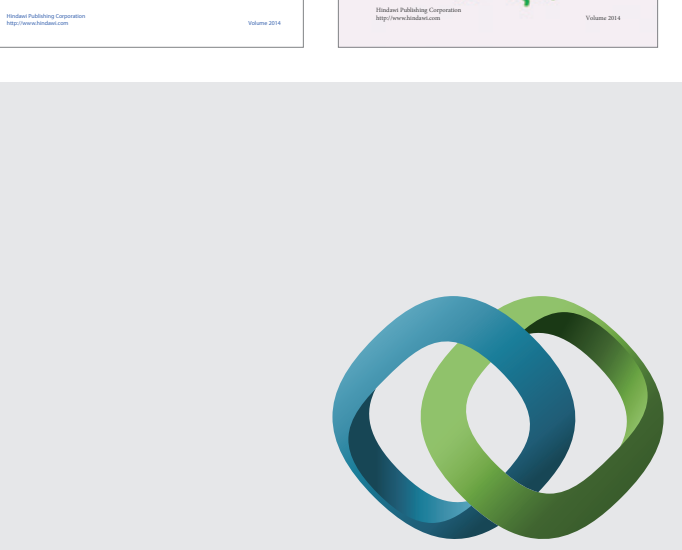

\section{Hindawi}

Submit your manuscripts at

http://www.hindawi.com
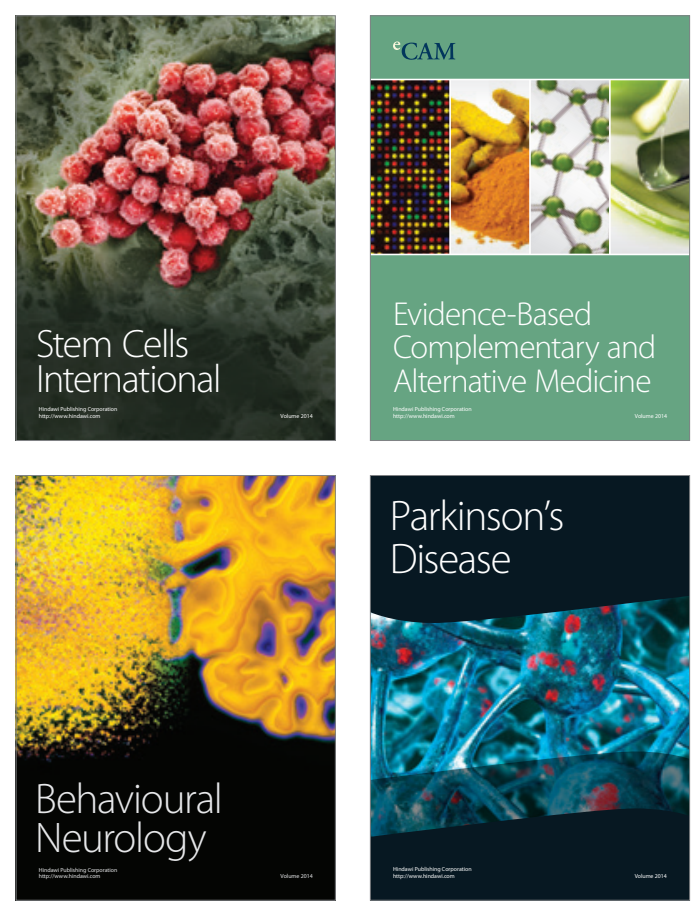

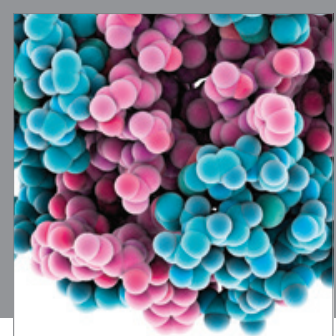

Journal of
Diabetes Research

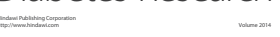

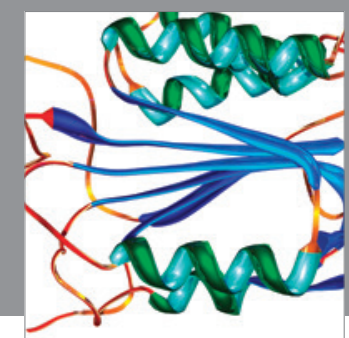

Disease Markers
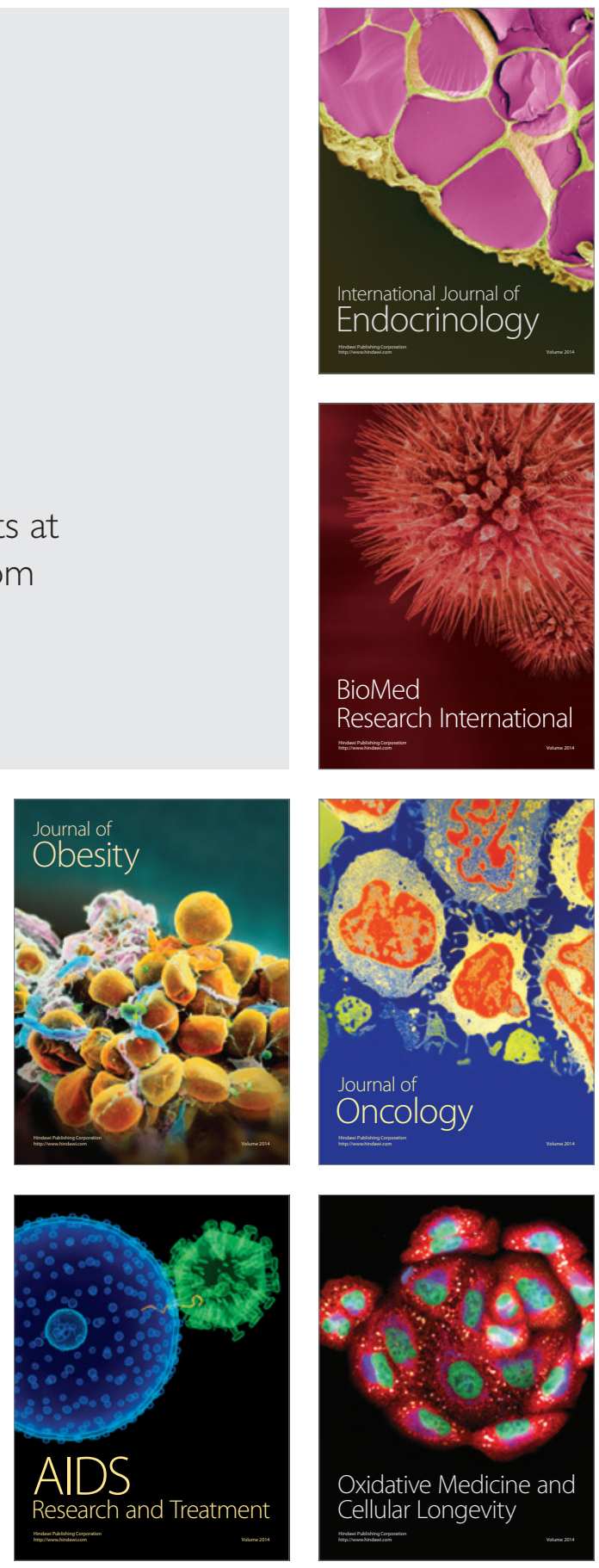